\title{
Research on Development Law of Overburden Rock Fracture in Steeply Inclined and Very Thick Coal Seam Mining
}

\author{
Weimin Cheng ${ }^{1, a}$, Lulu Sun ${ }^{1, b}$ \\ ${ }^{1}$ Key Laboratory of Ministry of Education for Mine Disaster Prevention and Control, Shandong University of Science \\ and Technology, Qingdao 266590, China \\ aemail: chengmw@163.com, bemail: sunsdust@126.com
}

\begin{abstract}
Compared with mining the horizontal coal seam and gently inclined coal seam, steeply inclined and very thick coal seam mining has many differences. Since the fracture development law is not clear, resulting in the application effect limitation of gas extraction, prevention and control of air leakage and other technics. In order to improve the efficiency of gas extraction and prevention of air leakage, laboratory similarly model test and numerical simulation were adopted to study the development law of overburden rock fracture, and the results with similarly model test and numerical simulation was identical. The result showed that: Its fracture development law showed a typical "V" structure, roof collapse and overlying strata movement rule were consistent well with separation and fracture development law. When mining the shallow level, the development degree of fracture was relatively low. With the increase of mining depth, the degree of development of fracture and separation rising. After mining 2 3 levels, vertical cracks appear in the working face overburden and it gradually developed up to the ground with the increase of mining depth. Compared with mining the shallow level, the range and development degree of roof separation in mining the deep shallow was higher.
\end{abstract}

Keywords - Steeply inclined and very thick coal seam; Fracture development; Similarly model test; Numerical simulation

\section{I.INTRODUCTION}

Steeply inclined coal seam mining has entered the stage of development of mechanized production since the 1970s, and it has developed greatly in The former Soviet Union and Ukraine. Subsequently, France, India and other countries also had conducted research and testing on Steep Seam related equipment, mining technology, safety and other aspects, and achieved some research results [2]. The development of Steep Coal Seam in China can be divided into four stages [1,2].

The mining method of steeply inclined coal seam are closely related to coal seam inclination, coal seam thickness and geological conditions, depth of burial, geological structure and gas content and other factors. Currently used methods can be roughly divided into the longwall mining method, horizontal slicing method and horizontal section top coal caving mining method three types. Horizontal section top coal caving mining method is suitable for steeply inclined and very thick coal seam, it has been further improved compared with the horizontal slicing method. The big dip of steeply inclined coal seam mining was deemed as favorable factors, and make full use of its feature that Seam collapse in an oblique direction. It has the advantage of large output, low roadway excavation rate, high degree of mechanization and high production efficiency. Meanwhile, the mining method just has a small scope (requirements for roof and floor stability, hard coal quality, low jointed degree of development, less tectonic belt, does not apply to Steep Seam which thickness less than $20 \mathrm{~m}$ ), and has deficiency of large initial investment, high coal dust and equipment installation and handling hard.

In terms of the mining way of steeply inclined and very thick coal seam horizontal section top coal caving, roof rock has an important effect on the overlying strata movement, fracture development and gas migration law. Now, study on collapse law of horizontal hard roof has been some progress [6-10], however, studies on inclined thick seam horizontal section top coal caving in overburden strata Movement and fracture development law has not been seen. And the fracture development law has an important influence on gas extraction, prevention and control of air leakage [11-14]. In terms of the mining rock research, similar material simulation test method as an important test of rock mechanics, can demonstrate the process of mining overburden migration and undermine intuitively. [15-16] Since the 1980s, discrete element particle flow code PFC has developed quickly, and it not only can assign to individual groups of particles and be suitable rock "separation" simulation and the large deformation situation, but also can observe crack initiation, propagation and coalescence of evolution visually by setting reasonable contact model. [17-18]. Above all, the similar material simulation and numerical simulation were adopted to research on development Law of overburden rock fracture in steeply inclined and very thick coal seam mining.

\section{II.DESIGN OF THE EXPERIMENT SCHEME}

\section{Similar material experiment}

Materials of similar material experiment mainly include two parts of the aggregate and cements [19-20]. Aggregate include river sand, talc and mica powder, etc. Cements include gypsum, calcium carbonate and cement, etc. In this experiment, the existing ratio of materials of coal seam-aggregate, which generally use sand, and the ratio of 
materials can only simulate the damage and motion law of coal and rock mass. According to the special mining method of thick coal seam, the relief of gas pressure and migration law of coal seam is different from the layer mining or the whole mining. By using coal as aggregate, it can provide the basis for the study of the law of gas coupling pressure relief and migration in the following simulation of similar materials. This paper adopted the method of orthogonal experiment with low strength ratio, and carried on the experiment and optimization of coal seam ratio with coal as aggregate in simulation test of similar materials. The experiment used cement, sand, water, activated carbon, coal as the ratio of coal seam.

Rock similar material ratio was determined according to the comprehensive stratigraphic column and the mechanical properties of rock stratum. The river sand was selected as the rock aggregate, the cement of similar material was gypsum, and added calcium carbonate, spread mica powder between

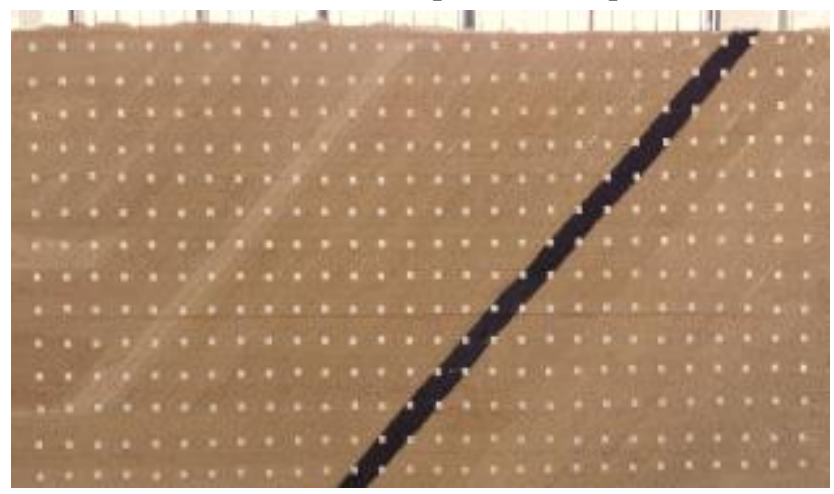

Fig. 1 Scene map of the paved model

\section{Numerical simulation experiment}

The main unit of PFC2D is two-dimensional circular particles and walls, both of which are rigid and non-deformable, but when the contact between the units occurs overlap also can appear [21]. In PFC2D calculation cycle, the force between the particles is guided by Newton's second law of force-displacement law, to simulate the contact between the particles and the relationship between movement and interaction. Based on force-displacement law, we can update the contact force between the particles, and seek the position of particles and boundaries by Newtonian law, and constitute a new contact. The basic principle is showed in Fig. 3. In PFC2D, Macro-mechanical characteristics of the rock is achieved by simple constitutive relation of each contact. Contact stiffness model determines the elastic relationship between contact force and relative displacement between the units.

Contact sliding model provides a relationship between tangential contact force and normal contact force, allowing relative sliding occurs between contacted sphere. Contact bond model limits maximum supported tangential and normal force. delamination to show a layered effect. According to the results of the model observation and record, demonstrated the cover rock movement and the crack growth the actual situations.

Due to the two-dimensional simulation test process is intuitive, convenient observation and meet the engineering accuracy requirement that can visually and comprehensively simulates the intended conditions of overlying strata failure and fracture development. The similar material experiment system of Shandong University of Science and Technology was used. The system size is $3 \mathrm{~m} \times 0.4 \mathrm{~m} \times 2.1 \mathrm{~m}$, with effective height of $1.8 \mathrm{~m}$, and is composed of a frame system, loading system and testing system.

The model paved all the rock layers above the coal seam mining according to the actual situation, so there is no need to impose additional load. Scene map of the paved model was shown in Fig. 1, partially enlarged view of the coal seam was shown in Fig. 2.

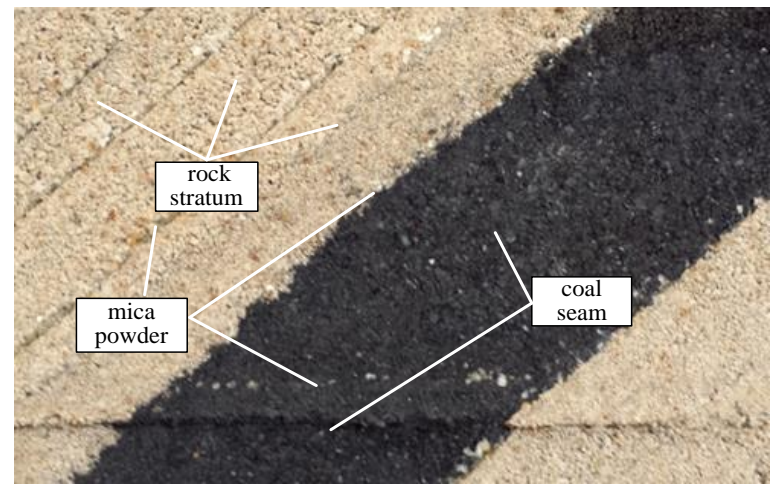

Fig. 2 Partially enlarged view of the coal seam

Contact bonding model is divided into the point bonding model and the parallel bonding model [22]. For the simulation of rock material, A bonding model was set between the particles in contact, which characterize bond strength of rock. Point bonding model can be regarded as a pair of spring with normal and tangential strength and have the specified normal and tangential bond strength, so that the point model can only transfer contact force, while the parallel bond model can be viewed as a series springs, which had uniform distribution on the contact surface. Those springs had a constant normal and tangential strength for center of the contact point. The relative motion in contact point will produce force and moment, as shown in Fig 4. Using the bond model, as long as the particles remain in contact, the contact stiffness is still valid no matter the bond was broken or not, which is inconsistent with the rupture mechanism of this point and rock. Using parallel bond model, the contact stiffness and bond stiffness together form the macroscopic stiffness and bond rupture lead to macroscopic stiffness decrease immediately. Using parallel bond in tensile or shear fracture can have a more realistic simulation of rock materials. Therefore we choose the parallel bond model. The established model using PFC2D software were shown in Fig. 5. 


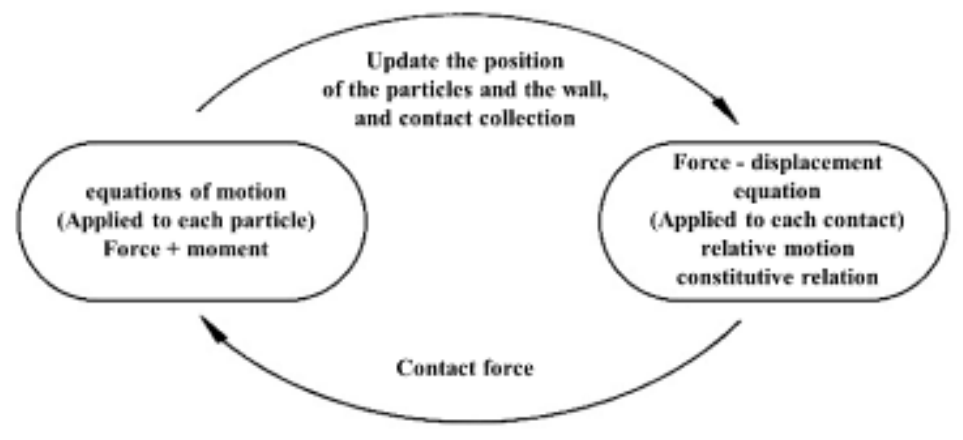

Fig. 3 Calculation cycle process of PFC2D

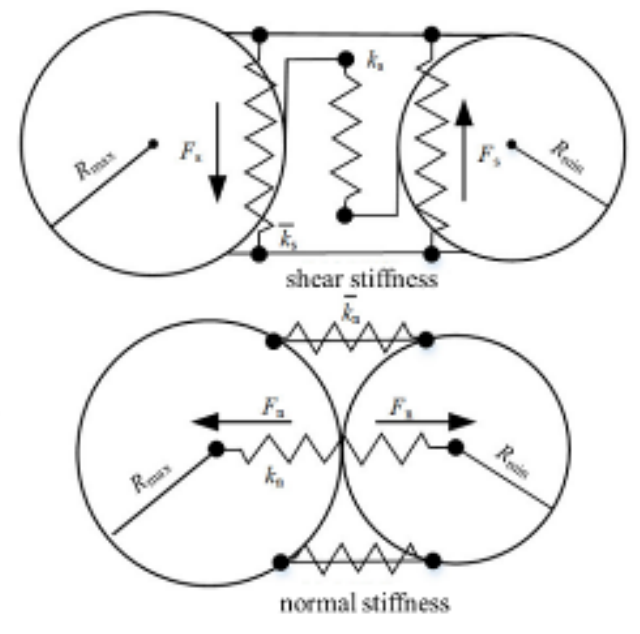

Fig. 4 Schematic model of parallel bond

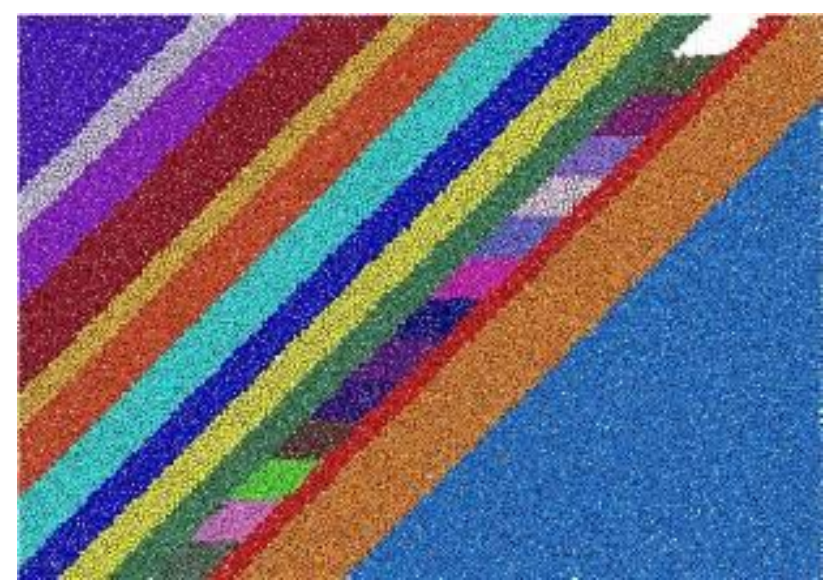

Fig. 5 PFC simulation model

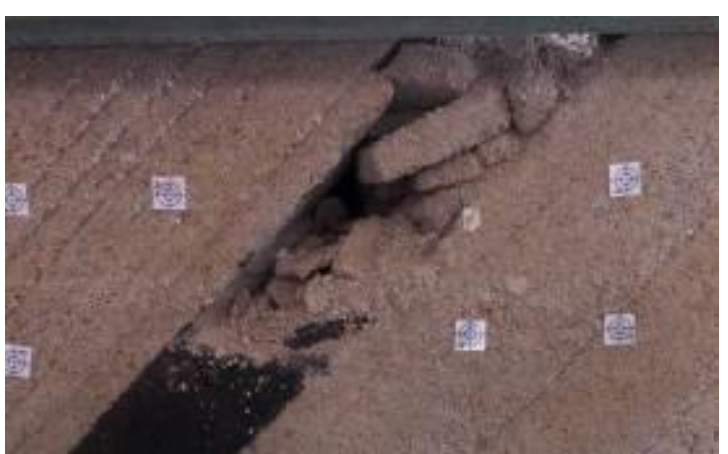

Fig. 6 Morphology of the overlying strata in third level mining (similar material experiment)

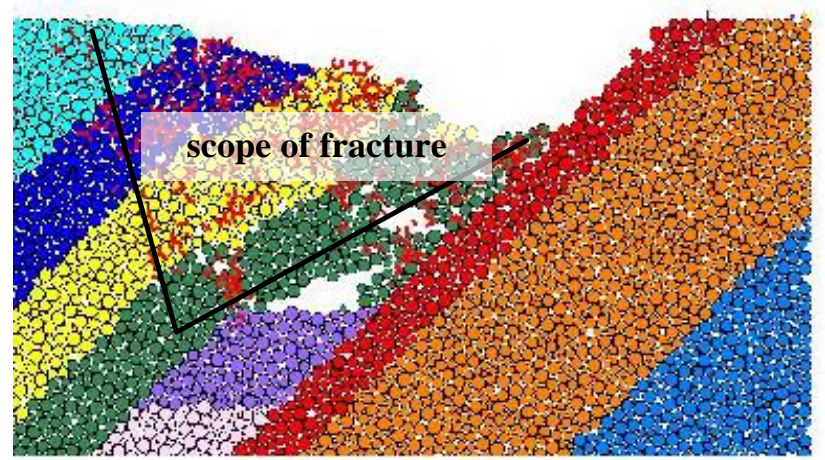

Fig. 7 Morphology of the overlying strata in third level mining (PFC simulation) 


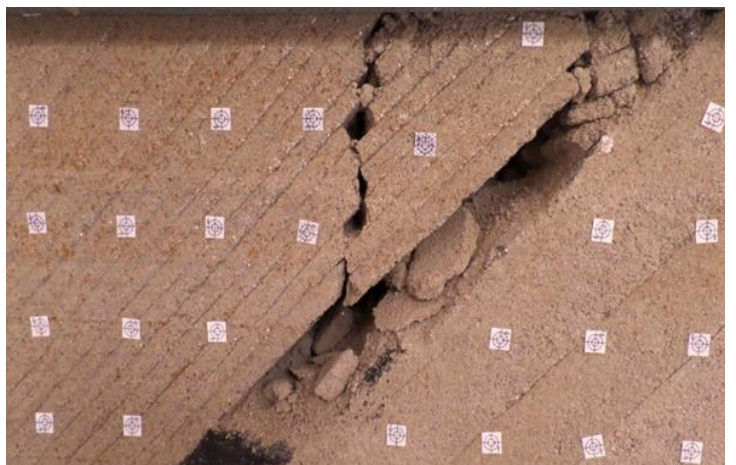

Fig. 8 Morphology of the overlying strata in fifth level mining (similar material experiment)

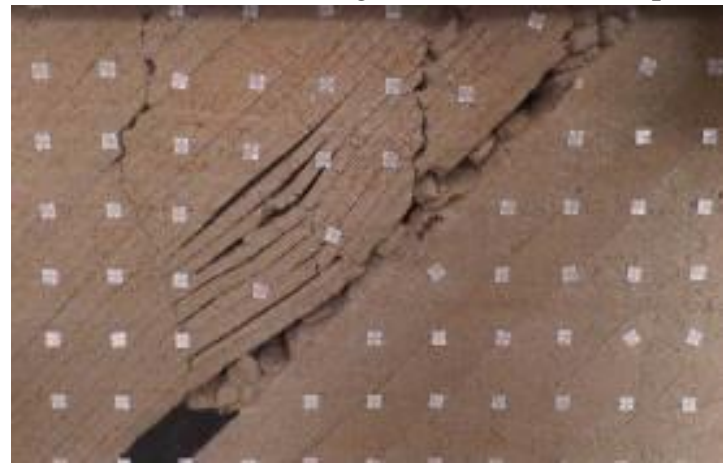

Fig. 10 Morphology of the overlying strata in seventh level mining (similar material experiment)

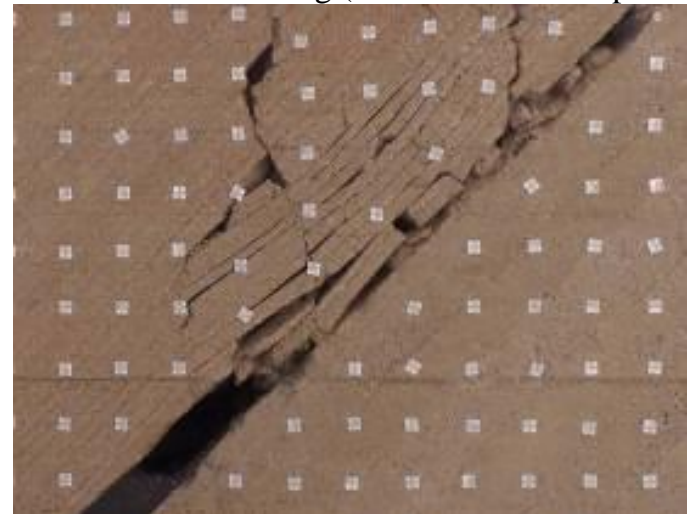

Fig. 12 Morphology of the overlying strata in tenth level mining (similar material experiment)

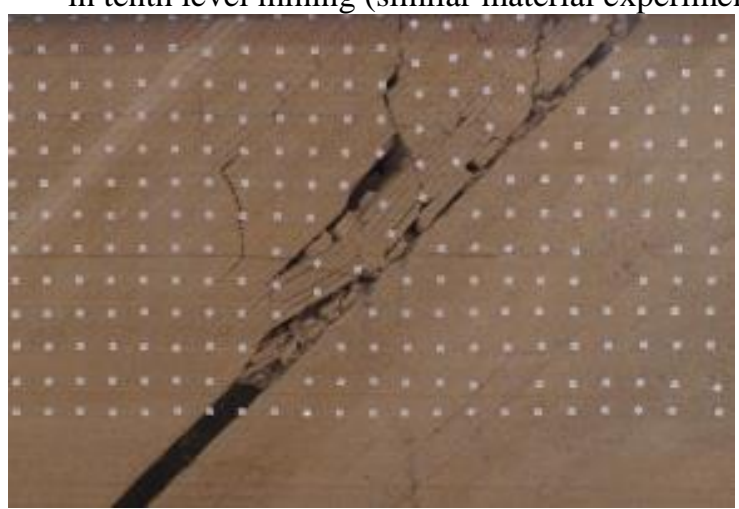

Fig. 14 Morphology of the overlying strata in twelfth level mining (similar material experiment)

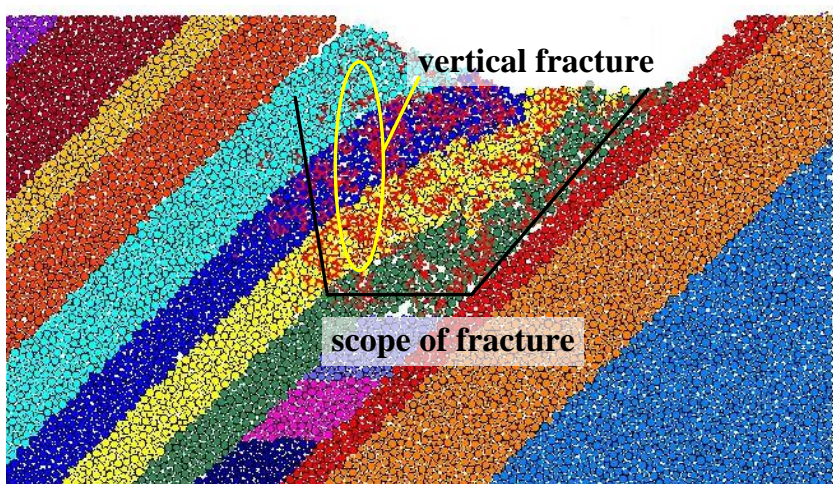

Fig. 9 Morphology of the overlying strata in fifth level mining (PFC simulation)

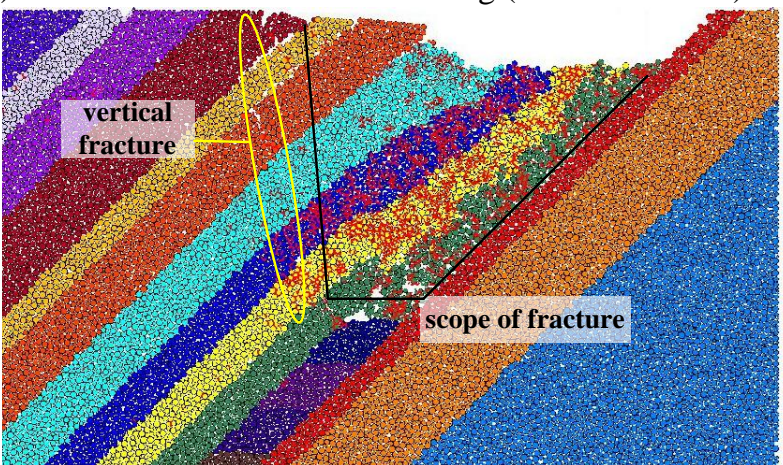

Fig. 11 Morphology of the overlying strata in seventh level mining (PFC simulation)

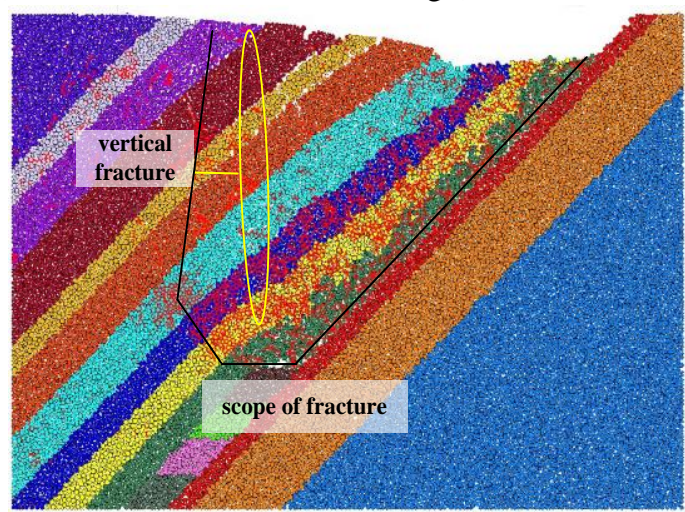

Fig. 13 Morphology of the overlying strata in tenth level mining (PFC simulation)

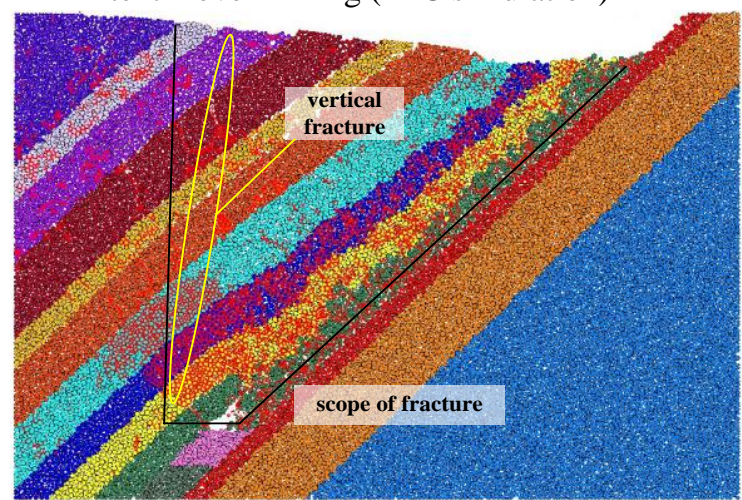

Fig. 15 Morphology of the overlying strata in twelfth level mining (PFC simulation) 


\section{III.RESULTS}

According to the mining stage of shallow level, middle level and deep level, the third, fifth, seventh, tenth, and twelfth levels of similar material simulation results and numerical simulation results were compared and analyzed, see in Fig. 6 Fig. 15.

\section{IV.DISCUSSION}

1) Roof collapse and overlying strata movement rule analysis

In shallow level connecting opencast coal mining, roof does not appear obvious separation and fracture. With the extension of $2 \sim 3$ mining level, roof layer and vertical crack gradually appear as the stable time increase. As overlying hard roof has weak structure surface separation, the lower part under hard and thick strata separate firstly, and the vertical fractures with roof movement will continue to grow and reach the surface of the earth. With rock mass migration, the separation height and degree gradually rising. Vertical fracture development degree increased and eventually reached a steady with the mining depth and stable time increasing. The roof layer development degree of deep level mining is higher than shallow mining.

2) The analysis of the development laws of separation and fracture

The development area in thick coal seam mining area is in the shape of "V" type, which is consistent with the roof and overburden rock caving, and the movement regularity is strong. The roof does not appear obvious separation and fracture when connecting with opencast coal mining, shallow level. After 2 3 levels of mining, the overlying strata will form obvious vertical fracture with the stable time increase. As overlying hard roof has weak structure surface separation, the lower part under hard and thick strata separate firstly, and the vertical fractures with roof movement will continue to grow and reach the surface of the earth. With rock mass migration, the separation height and degree gradually rising. Vertical fracture development degree increased and eventually reached a steady with the mining depth and stable time increasing. The roof layer development degree of deep level mining is higher than shallow mining.

After the ball add tape loading agencies, institutions force the ball the reverse spin, the ball close to pick the cue, pick the ball transfer fully energy to the ball, pick the ball effect is obvious stable. But it is found that the actual pick the ball after add tape loading agencies less than the theory calculated average distance.

\section{V.CONCLUSION}

1) The law of overlying strata and fracture in the extra thick coal seam mining is consistent between similar material simulation and PFC numerical simulation. The development area in thick coal seam mining area is in the shape of "V" type.

2) The roof and overlying rock caving strong motion, consistent with the separation and fracture development law;

3 ) The changes of separation and fracture development regularity have significant differences with mining depth. While overlying strata has no obvious separation in shallow mining level, the lower part under hard and thick strata separate firstly with the stable time increase, and the vertical fractures with roof movement will continue to grow and reach the surface of the earth. With rock mass migration, the separation height and degree gradually rising. Vertical fracture development degree increased and eventually reached a steady with the mining depth and stable time increasing. The roof abscission layer development degree of deep level mining is higher than in shallow mining.

\section{ACKNOWLEDGEMENT}

In this paper, the research was sponsored by the National Natural Science Foundation Project (Project No. U1261205\&51304128)

\section{REFERENCES}

[1] Gao Zhaoning, Shi Pingwu. Research on safe mining steep special thick seam using horizontal section top-coal caving [J]. Ground Pressure and Strata Control, 2005, 22(3): 18-20.

[2] Ma Peng. Research on the Gas Migration Mechanism of Steep Thick Seam in Fully Mechanized Top-coal Caving [D]. Xi`an: Xi`an University of Science and Technology, 2013

[3] Xie Wenjun, Giao Xiaoming, ShangGuan Kefeng. Long wall mechanized top-caving techniques along strike in steep-inclined thick coal seam[J]. Journal of China Coal Society, 2005, 30(5): 545-549.

[4] Ju Wenjun, Wei Dong, Li Qian. Seam gateway support technology for fully mechanized long wall top coal caving mining in horizontal slicing of deep inclined thick seam [J]. Coal Science and Technology, 2006, 34(5): 46-48.

[5] Li Kaixue. An Analysis of milling method of steep-incline seam and its ground pressure control [D]. Chongqing: Chongqing University, 2008

[6] Shi Hong, Jiang Fuxing. Analysis on rupture of hard and massive overlying strata in fully-mechanized sublevel caving face $[\mathrm{J}]$. Chinese Journal of Geotechnical Engineering, 2006, 28(4): 525-528.

[7] Wang Jiachen, Pan Weidong, Li Cheng. 3D numerical simulation of top coal caving with hard roof in gequan mine[J]. Journal of Mining \& Safety Engineering, 2008, 25(3): 272-276.

[8] $\mathrm{Wu}$ Yongping, Li Kaifang, Zhang Yanli. Simulation of hard roo weakening ahead of working face with fully mechanized caving [J]. Journal of Mining \& Safety Engineering, 2009, 26(3): 273-277.

[9] Li Shaogang, Li Dayong, Sun Zhongguang. Study on the time difference from initiating cracking to large area caving of thick-hard roof on shallow wongawilli face[J]. Journal of Mining \& Safety Engineering, 2013, 30(4): 538-541+547.

[10] Pan Yue, Gu Shitan. Analysis of bending moment, shear force, deflection and strain energy of hard roof at initial stage of cracking during periodic pressures[J]. Chinese Journal of Rock Mechanics and Engineering, 2014, 33(6): 1123-1134.

[11] Wei Yinshang, Deng Ganbo, Wu Xiaofan, et al. Analog simulation study on distributing law of gas in goaf of steep mining face $[\mathrm{J}]$. Journal of Hunan University of Science \& Technology(Natural Science Edition), 2009, 24(1): 13-17

[12] Sun Bingxing, Wang Zhongle, Wang Yongzhi. Research on Rational Position of Methane Drainage Boreholes in Full-mechanized Caving Mining Steeply-inclined Extremely-thick Coal-seam by Horizontal Sublevel Method [J]. Coal mining Technology, 2011, (6): 77-80.

[13] Chen Jianqiang. Analysis on Influence Factors of Gas Emission in Steep Extra-thick Coal Seam Mining [J]. Mining Safety \& Environmental 
Protection, 2015, 42(5): 92-95.

[14] Wang Gang, Xie Jun, Xue Sheng, et al. Laboratory Study on Low-temperature Coal Spontaneous Combustion in the Air of Reduced Oxygen and Low Methane Concentration[J]. Tehnicki Vjesnik, 2015, 22(5): 1319-1325.

[15] Zuo Baocheng, Chen Congxin, Liu Caihua, et al. Research in similar material of slope simulation experiment[J]. Rock and Soil Mechanics, 2004, 25(11): 1805-1808.

[16] Wang Chongge, Wang Lili, Song Zhenlian, et al. Testing study on 3D similar material simulation for shallow coal seam mining[J]. Chinese Journal of Rock Mechanics and Engineering, 2004, 23(Sup 2): 4926-4929.

[17] Wang C, Tannant D D, Lilly P A. Numerical analysis of the stability of heavily jointed rock slopes using PFC2D [J]. International Journal of Rock Mechanics and Mining Sciences, 2003, 40(3): 415-424.

[18] Wang Tao, Zhou Weibo, Chen J, et al. Simulation of hydraulic fracturing using particle flow method and application in a coal mine [J]. International Journal of Coal Geology, 2014, 121: 1-13.

[19] Kang Xiangtao, Huang Gun, Deng Bozhi, et al. Experimental study on similar material for simulating raw coal [J]. Journal of Northeastern University (Natural Science), 2015, 36(1): 138-142.

[20] Liu Liangliang, Wang Hailong, Liu Jiangbo, et al. Low strength similar material proportioning test based on orthogonal design [J]. Journal of Liaoning Technical University (Natural Science), 2014, 33(2): 188-192.

[21] Itasca Consulting Group Inc. Manual of particle flow code in 2-dimension (Version 3.10) [M]. Minneapolis: Itasca Consulting Group Inc, 2005.

[22] Cho N, Martin C D, Sego D C. A clumped particle model for rock [J]. International Journal of Rock Mechanics \& Mining Sciences, 2007, 44: 997-1010. 